\title{
Docência, cinema e televisão: questões sobre formação ética e estética
}

\author{
Rosa Maria Bueno Fischer \\ Universidade Federal do Rio Grande do Sul, Programa de Pós-Graduação em Educação
}

\section{Introdução}

Pensar modos de operar com o cinema e a televisão como fontes especiais de educação do olhar e de transformação ética e estética de si mesmo é a proposta deste artigo. Sem a pretensão de oferecer fórmulas, nem quanto à formação dos educadores muito menos quanto a uma possível metodologia de análise de imagens audiovisuais, o objetivo é imaginar a possibilidade de estabelecer relações entre formação docente e filosofia - tratando ambas como um trabalho de operação sobre si, na esteira do que nos ensinaram Michel Foucault e os pensadores clássicos gregos e romanos. Para tanto, a argumentação feita aqui tem como ponto de partida importantes elaborações do filósofo francês, as quais são pensadas em relação a algumas produções recentes do cinema e da TV, tendo como foco a formação de professores. ${ }^{1}$

\footnotetext{
${ }^{1}$ Versão modificada do trabalho apresentado na $30^{\mathrm{a}}$ Reunião Anual da ANPEd, com o título Cinema e TV na formação éticoestética docente (Fischer, 2007). Está diretamente relacionada à pesquisa "Educação do olhar e formação ético-estética: cinema e
}

A meu ver, um dos livros mais fascinantes publicados no início deste século, na área da filosofia, é $A$ hermenêutica do sujeito, de Michel Foucault (2004b), no qual estão transcritas as aulas do curso que o filósofo proferiu no Collège de France em 1982. Essa obra - sem temer redundâncias - efetivamente opera algo especial em nós, naqueles que a leem e a estudam. Nela encontramos um Foucault que, sem deixar de estar ocupado com a leitura crítica e política dos dispositivos de poder que tanto o marcaram em sua trajetória acadêmica e existencial, concentra-se nas questões éticas e estéticas da produção de si mesmo. Ele busca, nos filósofos da Antiguidade clássica grega e romana, fonte para pensar não mais prioritariamente o problema das diferentes formas de sujeição, mas antes o tema dos modos de subjetivação. Estes, na leitura de Foucault, apontavam para práticas de si mesmo e práticas da verdade nas quais estariam mais evidentes formas de liberdade do sujeito do que exatamente processos de aprisionamento.

juventude”, aprovada em 2007 pelo Conselho Nacional de Desenvolvimento Científico e Tecnológico $(\mathrm{CNPq})$, agência à qual agradeço pela bolsa de Produtividade em Pesquisa e pelo financiamento. 
Trata-se de uma dimensão nova em sua obra: deixar que o político seja também impregnado por indagações éticas e, nesse caminho, pensar na possibilidade de um trabalho sobre si mesmo para além de assujeitamentos, na direção de uma estética da existência.

Seguimos Foucault nessa tentativa de pensar o presente, de fazer a história do tempo em que vivemos e de imaginar, a partir da leitura dos filósofos antigos (como Marco Aurélio, Sêneca, Epicteto, Epicuro e Plutarco, entre tantos outros), práticas que hoje poderiam talvez estar na ordem de nossos exercícios cotidianos, como professores e pesquisadores. Práticas diretamente relacionadas à nossa formação ético-estética. Práticas em torno das quais se poderia falar em coragem da verdade. Práticas que colocam em jogo complexas relações entre filosofia e espiritualidade, entre cuidado de si e conhecimento de si - oposições que, na realidade, marcam as diferenças entre a Antiguidade e a filosofia moderna. Naquela, ter acesso à verdade dependia diretamente de um prévio trabalho ético sobre si mesmo, ou seja, de uma espécie de conversão de si e a si, o que não ocorre na modernidade; nesta, o ponto de partida é justamente o próprio acesso à verdade e ao conhecimento. Naquela, o conhecimento estava subordinado ao cuidado de si; nesta, tal relação se inverte completamente, e conhecer toma as rédeas da vida e da ciência.

Entendo que, no momento presente, perguntas e propostas sobre nossa formação ético-estética se tornam cada vez mais urgentes - de modo particular quando se trata da relação entre professores e alunos, adultos e jovens, educadores e crianças. Assim é que trago Foucault e sua hermenêutica do sujeito para pensar esse entrelugar de técnicas de dominação e de técnicas de si, ambas historicamente datáveis, esse entrelugar em que emerge o sujeito, essa dobra que está sempre por se fazer, que se debate, se movimenta e cria no espaço híbrido de processos de subjetivação e de procedimentos de sujeição. Desejo pensar aqui esse entrelugar referindo-me especificamente à docência como um lugar privilegiado de experimentação, de transformação de si, de exercício genealógico - lugar de indagação sobre de que modo nos fizemos desta e não daquela forma; de que modo temos aceitado isto e não aquilo; de que modo temos recusado ser isto ou aquilo, no caso, como docentes. Lugar de onde talvez seja possível não exatamente pensar nossos limites e as forças que nos constrangem, mas as condições e possibilidades infindas, imprevisíveis e indefinidas de nos transformarmos e de sermos diferentes do que somos.

Nos textos clássicos, dos gregos e romanos antigos, aprendemos junto com Foucault a importância de nos apropriarmos de discursos verdadeiros para darmos conta tanto dos acontecimentos externos como daquilo que vivemos internamente. Esse era (e seria hoje, numa configuração totalmente diversa daquela antiga?) o caminho do cuidado de si, que prevê uma série de exercícios e práticas, os quais ao fim e ao cabo se fazem para que estejamos preparados para o que virá, o que nos pode suceder. Tais práticas e exercícios são aprendidos, vividos, sempre na relação com o outro, o mestre, o discípulo - uma relação que envolve trabalho sobre o corpo e a alma, ao mesmo tempo em que não separa logos e ação.

Proponho-me a discutir aqui o tema da formação ético-estética docente tendo como ferramenta teórica principal Michel Foucault e sua hermenêutica do sujeito, utilizando, digamos, como material empírico, algumas narrativas audiovisuais do cinema e da televisão. Suponho que poderia fazer parte importante da formação docente a educação do olhar, a educação de sensibilidade, a educação ética, cuja fonte poderia ser, dentre tantos possíveis, alguns exercícios de imersão nas linguagens audiovisuais: exercícios de entrega aos sons, movimentos, diálogos e cores das imagens do cinema e da televisão; exercícios de entrega a narrativas que fogem aos esquemas convencionais das chamadas estruturas de consolação.

Tais exercícios, a meu ver, poderiam comparar-se, com todas as salvaguardas necessárias, a uma espécie de práticas consigo mesmo, catapultadas pelo acesso a produções fílmicas ou televisivas que escapam aos padrões convencionais e que sugerem ao espectador uma elaboração ética de si mesmo - absolutamente necessária em nossos tempos. Tempos de impunidade desmesurada, tempos de exposição de si mediada 
por sofisticadas tecnologias digitais, em meio a um excesso de imagens e de informação; tempos de quase-anulação de referências éticas para gerações mais jovens; tempos de imensa dificuldade de discernimento e hierarquia entre textos e imagens que se confundem diante de nossos olhos, reduzidos muitas vezes a uma plana mesmice - seja pelo excesso de imaginário produzido, seja pela falta de instrumental para minimamente operar seleções com algum critério.

Vamos entender aqui formação como uma operação que se dá para além do institucional (escola, igreja, família, por exemplo), embora tais espaços não sejam jamais ignorados; para além de um sistema de autoridade, normativo ou disciplinar; formação assumida como uma escolha da própria existência, como busca de um estilo de vida, de um cuidado consigo, que de maneira alguma poderia ser identificado com o culto narcísico de nossos tempos. Ao contrário, na ética foucaultiana a busca de constituição para si de um estilo de vida teria a ver com a dinamização de uma capacidade de provocar, de duvidar, de dedicarse a si mesmo com vigilância e esforço, com vigor, com entrega ao genuíno desejo de desaprender o que já não nos serve e municiar-nos de discursos que nos incitam a agir eticamente e a nos transformar. Todo esse trabalho sobre si será sempre atravessado pela presença do outro, do mestre, daquele a quem recorremos para nos apossarmos de discursos verdadeiros. Ao mesmo tempo, todo esse trabalho não partirá de noções cristalizadas; antes consistirá em breves e cotidianos esquemas práticos de vida, embora estes estejam vinculados a uma rigorosa construção filosófica - o que não seria em si contraditório, como veremos adiante.

Mas quais discursos? Quais verdades? Se é totalmente impensável viver sem, de alguma forma, estarmos sujeitos a discursos; sem, de alguma forma, sermos assujeitados por verdades que circulam e que se cristalizam nos mais diferentes campos de saber e nas mais variadas situações institucionais, também é certo que, como escreve Foucault, a verdade é deste mundo, os discursos são construídos historicamente. Assim sendo, o grande trabalho sobre nós mesmos será pensar como nos tornamos o que somos, que discursos nos subjetivam, a que verdades nos amarramos (ou: que verdades nos amarram?). Em suma: a grande tarefa será montar nossa maleta de discursos verdadeiros, elegendo aqueles que menos cingem nossa subjetividade (Foucault, 1995), aqueles que de alguma forma apontam para uma espécie de liberdade - liberdade que não se separa de uma ética, relacionada a práticas de cuidado consigo mesmo e pensada para nossa época, com inspiração explícita em Foucault e nos filósofos da Grécia e Roma clássicas.

\section{Despertar de uma paixão: ética da conversão a si}

Um bom romance e um bom roteiro de filme não podem prescindir de pelo menos um personagem remetido à própria transformação, a uma experiência de si que o subverte, que faz dele algo diferente do que era. Lemos em A hermenêutica do sujeito uma passagem brilhante, na qual Foucault cita um estudo sobre a filosofia helenística em que o tema da conversão é tratado negativamente a partir da imagem do pião, esse brinquedo que gira sobre si mesmo, movimenta-se em várias direções involuntariamente, ao sabor de uma ação externa (Foucault, 2004b, p. 255). A ideia desenvolvida é a de que, ao contrário do pião, o movimento a ser feito é de nos centrarmos em nós mesmos, no nosso centro, fazermos a virada em direção a nós próprios. O que aprendemos na cultura helenística é justamente operar um deslocamento daquilo que não depende para aquilo que depende de nós, num movimento de adequação de si a si mesmo: muito mais do que conhecer, do que obter dados sobre uma determinada situação, tratar-se-á de fazer um exercício ascético (no sentido grego clássico) de equipar-se, num processo que Foucault chamou de autossubjetivação.

Poderíamos tomar como exemplo inúmeros filmes para desenvolver os argumentos a que nos propomos neste trabalho. Lembremos aqui uma produção recente, norte-americana e chinesa, de 2006, Despertar de uma paixão, ${ }^{2}$ que se passa no interior da China nos

\footnotetext{
${ }^{2} \mathrm{O}$ título original é Painted veil (O véu pintado), adaptação
} do romance de W. Somerset Maugham. Estrelado e produzido por 
anos de 1920. O casamento sob pressão de uma jovem fútil da burguesia inglesa, Kitty (Naomi Watts), com o bacteriologista Walter (Edward Norton), acaba por conduzir os dois ao interior da China, onde há uma epidemia de cólera. O episódio de traição de Kitty e a dolorosa experiência de desamor para ambos teriam a ver com a metáfora da vida como um véu pintado pelas convenções sociais, como refere o crítico Luis Carlos Merten (2007). Eis o momento da conversão: acompanhamos a transformação dos dois personagens, visível na expressão do olhar, nos gestos, nas suas incursões por ruelas em meio à pobreza e à morte: rancor e ódio, desamor e raiva dão lugar à compaixão, à maturidade, à decisão e especialmente ao afeto.

Poderíamos dizer que a plasticidade das belíssimas paisagens filmadas por Curran, aliada à delicadeza da interpretação dos atores principais, interpelam o espectador e o arrebatam em direção à experiência da conversão, aquela experiência radical de abandonar o olhar curioso para todos os lados e entregar-se inteiramente a si. Tal atitude, não paradoxalmente, é provocada porque há concomitantemente uma entrega ao outro que provoca em nós o pensamento, a interdição do que éramos então como inércia. As mais de duas horas de duração do filme fazem-se outro tempo, menor e mais intenso, na medida em que experimentamos o belo e o sublime da conversão; na medida em que sabemos de um mundo de convenções que, mesmo na mais miserável das realidades, pode ser subvertido, colocado às avessas, de cabeça para baixo. O longínquo do território chinês dos anos de 1920 funcionaria talvez como um espaço vazio, construído ao redor da personagem Kitty, que, exatamente por concentrar-se em si mesma, se descobre outra e com o outro.

Nesse processo de conversão, um elemento indispensável a considerar é a imagem cotidiana da morte, tão presente nos exercícios ascéticos propostos pelos filósofos clássicos estudados por Foucault. Interessante como o filme de Curran, irmanando tempos tão díspares como os primeiros séculos da nossa era, os

Edward Norton e Naomi Watts, o filme é dirigido por John Curran, uma coprodução China-Estados Unidos (2006). anos de 1920 e o momento contemporâneo do espectador, pensa a morte: o diretor (e o romancista também) expõe os dois personagens à morte, literalmente (Norton morre ao final, de cólera, como os pobres chineses de quem cuida), sem que isso se torne nem uma tragédia melodramática, nem uma manifestação de bom-mocismo demagógico.

O percurso vivido pelos dois personagens é de provas radicais, às quais ambos se entregam como se assumissem para si mesmos, real e metaforicamente, que a morte não só é possível mas necessária, e é preciso estar preparado para ela. Meditar sobre esse acontecimento de "gravidade absoluta" - como escreve Foucault a respeito dos exercícios propostos por Sêneca nas cartas a Lucílio (Foucault, 2004b, p. 579s.) -, no caso do casal do filme, acontece por força do cotidiano que eles vivem, mas é mais do que isso: acontece com tal intensidade e dignidade que lhes permite a transformação de si próprios. Não importa tanto o fato triste da morte de Norton - essa seria a leitura convencional, apropriada a uma telenovela ou a um dramalhão romântico hollywoodiano. Aqui, o que é depositado ao olhar do espectador é de outra ordem: trata-se da vitalidade de uma mulher e de um homem que, nas condições mais adversas, tornam-se diferentes do que eram até então.

Talvez possamos trazer aqui um clássico do cinema, Morte em Veneza, ${ }^{3}$ e associar essa narrativa a Despertar de uma paixão. As imagens de Visconti, na célebre cena inicial, em que o personagem principal chega de barco à cidade, não são apenas belas imagens. Como escreve Alain Badiou, a magistral sequência é muito mais do que isso: "É uma espécie de poema mortal, uma travessia melancólica e grandiosa” (2004, p. 43, tradução livre). Nos dois filmes, paisagens belíssimas jamais se reduzem a mera decoração: a integração entre cenário, rostos, cores e, no caso do filme de Visconti, também e especialmente a trilha sonora (o adágio da Quinta Sinfonia de Mahler), amalgamam-se numa síntese primorosa de arte pictórica, plástica, musical e dramática. Diria também filosófica, no sentido usado

3 Produção de 1971, baseada no romance homônimo de Thomas Mann. 
por Badiou, de que só há filosofia quando estão em jogo no pensamento rupturas e acontecimentos postos em relações paradoxais. Tornar visível o tempo; fazer arte de "massas"; promover a distância e a identificação; morrer e resistir à morte; pensar a exceção, o extraordinário e escolher contra o continuísmo da vida institucionalizada - esses seriam alguns dos paradoxos do cinema de arte, visto como filosofia, já que trata de relações que seriam de fato não-relações (Badiou, 2004).

Parodiando Marilena Chauí, a pergunta é: o que, afinal, a filosofia do cinema (ou, para Chauí, a filosofia da visão) ensina à filosofia? Ela responde: "Que ver não é pensar e pensar não é ver, mas que sem a visão não podemos pensar, que o pensamento nasce da sublimação do sensível no corpo glorioso da palavra que configura campos de sentido a que damos o nome de ideias" (Chauí, 1999, p. 60). Ou ainda o que a filosofia do cinema ensina à educação? Penso que ensina a ir além das interpretações, da leitura das entrelinhas, do não-dito. Talvez ensine uma generosidade esquecida, de olhar o que está diante de nós e nos entregarmos ao que aquela peça audiovisual oferece, sem necessariamente desejar uma espiadela curiosa por trás das cortinas para saber o que realmente as imagens queriam dizer. Esse exercício não é tão fácil assim, pois exige o esforço de fugir aos apelos imediatos das explicações causais, consoladoras, dos julgamentos apressados ou rígidos, para abrirmos todos os sentidos ao que lemos e vemos, empregando nessa tarefa nossa capacidade intelectiva, nossa bagagem de informações com o objetivo de fazer da experiência de ver também um espaço privilegiado de transformação de nós mesmos.

\section{Pequena Miss Sunshine: estética do silêncio e subversão da lógica do vencedor}

A menina Olive (Abigail Breslin), de Pequena Miss Sunshine, ${ }^{4}$ é o personagem central de uma história

\footnotetext{
${ }^{4}$ Produção de 2006, dos norte-americanos Jonathan Dayton e Valerie Faris. premiada como melhor filme do Festival de Cinema Norte-Americano de Deauville, na França. Concorreu ao Oscar de melhor filme em 2007.
}

que, com muito humor, desmancha diante de nossos olhos valores dominantes, cristalizados em práticas, aliás, não exclusivas da sociedade norte-americana. Assim, por exemplo, vemos desabar - na figura do pai de Olive - o culto californiano do eu, associado ao ensino e à aprendizagem de como vencer na vida, prática em vigência desde os anos de 1970 e aprimorada hoje nas mais diferenciadas formas de gerir recursos humanos em grandes e pequenas empresas, que tem como correlatos milhares de publicações de autoajuda em todo o mundo. Mas o mais rico nesse filme é que, sem moralismos ou maniqueísmos de qualquer nuance, os personagens são e não são, ao mesmo tempo: a menina deseja sinceramente participar de um concurso mirim de beleza, e ninguém na família questiona nela a total falta do necessário physique du rôle; as aulas de como vencer na vida são dadas por um homem maduro cuja família está literalmente falida - o pai é o protótipo do perdedor, mas seu sonho é publicar um best-seller de autoajuda; o avô é drogado e às escondidas prepara a performance sensual da pequena candidata a miss; há ainda um tio suicida e gay, também o irmão Dwayne, um adolescente revoltado; e, finalmente, a mãe, não por acaso uma mulher, a buscar uma ordem para a total desestruturação daquela família de desajustados.

Por que trago esse filme para pensar a formação ética e estética de professores? Talvez para pensar pelo menos duas questões principais relativas à educação do olhar: a imagem da criança (no caso, Olive) e as metáforas do silêncio (na atuação do adolescente Dwayne, interpretado por Paul Dano) e da travessia (a família literalmente atravessa os Estados Unidos numa Kombi caindo aos pedaços). Em primeiro lugar, com sutileza - pode-se dizer, sutileza afetiva - os diretores escolhem uma atriz que é criança mesmo, não é vestida de adulta nem para efeito do concurso, como suas concorrentes e como grande parte das crianças em vários lugares do mundo. Há uma criança que irrompe na tela e que, como escreve Fabiana Marcello, está ali na sua condição de imagem cinematográfica: nada a ser ali "reconhecido", mas sim a ser recebido na condição de algo que se torna o que é, como acontecimento, como multiplicidade (Marcello, 2008). Ou seja, o corpo da 
menina que vemos (da atriz, da personagem, de ambas na narrativa fílmica) é o corpo que nos olha; ou melhor, é o olho que nos olha também: para além da técnica específica, das escolhas dos diretores, da montagem, ver é sempre uma duplicidade; ser visto também.

Em outras palavras, o cinema (e este filme em especial) nos coloca diante da infância, de seu comportamento, de sua corporeidade, de uma gestualidade própria que, como escreve Larrosa (2006), só pode ser vista, mas não compreendida. O autor defende que não podemos ter acesso à infância - como tantos estudiosos tentaram e continuam tentando conseguir. E o cinema, por mais que seja o próprio lugar da exposição desse outro infantil, por mais que seja revelação, ${ }^{5}$ permanece para nós como mistério, como silêncio, numa gestualidade sem significado e para a qual não há que se buscar "sentidos". Durante a travessia na Kombi enferrujada, a menina Olive se aproxima do irmão que, próximo da estrada, se recusa a seguir viagem. Ele não fala, apenas escreve bilhetes à família, e a única personagem que consegue mobilizar Dwayne é Olive: ela também em silêncio, apenas firme no olhar. Toda a gestualidade dessa cena pode ser vista e revista, descrita em dezenas de palavras, mas não capta a grandiosidade mínima do gesto de afeto mais genuíno ali exposto. Trata-se da criança como acontecimento, como abertura, como não-necessidade de explicações ou conclusões.

Haveria um mutismo enigmático das imagens da criança no cinema. Neste filme em especial, tal mutismo é literalmente narrado por meio do personagem Dwayne, o adolescente ainda identificado com a criança, que se comunica apenas por bilhetes escritos, praticando um legítimo voto de silêncio. Essa gestualidade parece marcar toda a narrativa, como que a colocar diante de nossos olhos não apenas mais um exemplo de rebeldia adolescente: a repetição do gesto de Dwayne teria, a meu ver, uma função metafórica; talvez poderia ser vista como "uma relação que é uma não-relação”, um silêncio mais contundente que toda

${ }^{5}$ Ver, a propósito do cinema como revelação (ou engano), o texto de Ismail Xavier (2003). a loquacidade do pai palestrante de autoajuda. Um silêncio pedagógico - lembrando aqui da prática do silêncio pitagórico, estudada por Foucault, que naquelas condições históricas específicas existia como exercício fundamental para os discípulos, diante da palavra do mestre. O silêncio como exercício de memória, como abertura de um espaço interno para experimentar e elaborar a si mesmo - condição básica para escutar “a palavra verdadeira” (Foucault, 2004b, p. 501-503). No turbilhão da viagem da grande família, da verborragia paterna, aqui parece emergir uma espécie de mestria, mesmo que frágil: o menino, ele próprio, escuta a si mesmo ao se calar.

Finalmente, a metáfora da travessia: no filme, a vida daqueles personagens acaba sendo experimentada como prova, como formação. Todos são submetidos a uma prova aparentemente absurda: conduzir a menina Olive ao concurso de miss, fadado ao insucesso desde a partida, tanto quanto o sonho do best seller paterno. A riqueza filosófica, se podemos assim dizer, está novamente numa relação que é não-relação - no caso, a miss sem corpo de miss e a aposta em vencer na vida sem as mínimas condições para tanto. Mas o que sucede é que, na travessia, todos os personagens de alguma forma se transformam; de alguma forma, ocupam-se consigo, submetem-se a duras provas, inclusive a da morte - e tudo é narrado com leveza e humor primorosos, que não só fazem uma ácida crítica aos valores da sociedade norte-americana como, de modo mais amplo, falam da vida como formação. Subverte-se completamente a lógica da sociedade do vencedor, sem cair na lógica oposta, a do perdedor, do coitadinho, nem nos gestos de miserabilidade demagógica. A subversão aqui é correlata da transformação de si.

\section{Cena Aberta: desmanche das formas instituídas}

Na televisão brasileira, são várias (não exatamente muitas) as produções de que poderíamos nos valer para pensar sobre imagens e cenas que nos remetem a propostas de uma arte de viver - estas talvez marcadas pela memória do que nos deixaram os filósofos antigos, os quais não separavam o trabalho sobre si mesmo 
da escolha de discursos verdadeiros e de exercícios e regras para fazer da própria vida algo de "bom e belo" (Foucault, 2004b, p. 513). Tratarei aqui, portanto, da análise de um produto da televisão brasileira, procurando "conversar" com Foucault e os filósofos clássicos e trazendo para o centro da discussão exatamente o que o pensador francês salientou na entrevista intitulada A ética do cuidado de si como prática da liberdade: nesse texto, Foucault (2004a) lembra que as práticas de si tiveram, nas civilizações antigas gregas e romanas, certa autonomia em relação aos jogos de poder e saber instituídos. E foi exatamente isso que fascinou o autor de Vigiar e punir (Foucault, 2007), obra em que enfatizou justamente uma outra faceta do poder: as práticas coercitivas. Em A hermenêutica do sujeito (2004b), emergem os jogos de verdade como práticas de formação do sujeito, como exercícios de elaborar a si, transformar-se, atingir algo mais a partir do que se é. E é disso que falaremos aqui, supondo que seja possível discutir tal temática a partir de algo tão prosaico como um programa de televisão.

De um conjunto não tão extenso, mas mesmo assim significativo, selecionei uma produção pouco conhecida da maioria dos telespectadores brasileiros: a série Cena Aberta, em que a TV Globo ofereceu aos espectadores um tipo de produção muito especial: os roteiristas da série adaptaram obras literárias para a TV misturando documentário, reportagem e ficção, com a atuação principal de Regina Casé. ${ }^{6} \mathrm{O}$ público

\footnotetext{
${ }^{6}$ No primeiro episódio da série, que teve o mesmo título do romance de Clarice Lispector, a produção trouxe até o estúdio mais de uma dezena de moças, moradoras da cidade do Rio de Janeiro, todas vindas de estados do Nordeste brasileiro. Elas contracenaram com Regina Casé e com alguns atores, literalmente lendo e interpretando trechos da obra de Clarice - de tal modo que a história da personagem Macabéa foi ao mesmo tempo lida, relida, interpretada dramaticamente, ora com atuação das moças, ora com a atuação dos atores especialmente convidados. Houve inclusive uma alteração no próprio final dado por Clarice à personagem Macabéa. Várias linguagens e várias formas de leitura de um romance se cruzaram no programa, sem que houvesse qualquer perda de "autenticidade" em relação ao romance adaptado.
}

teve acesso a quatro adaptações em que roteiristas, diretor, atores, produtores - enfim, toda a equipe de criação - dedicaram-se a subverter linguagens - da TV, da literatura, do teatro, do próprio jornalismo. Ou seja, temos aqui, mais uma vez, o paradoxo, o paradoxo da relação que é não-relação: na TV, literatura que não é literatura. Ficção que é e não é reportagem nem "realidade". Se nos detivermos no episódio A hora da estrela, teremos o universo de Clarice Lispector, desse romance em particular, desmanchado diante de nossos olhos, na figura das inúmeras Macabéas convidadas por Regina Casé, também elas nordestinas retiradas para o Rio de Janeiro. ${ }^{7}$ O desmanche das cenas televisivas, a possibilidade de ver por dentro a mágica da transformação de livro em roteiro de TV, da criação de figurinos que transformam em cariocas ou nordestinas - tudo isso funciona na produção como mote para adentrarmos a ficção de Clarice e sermos de fato olhados por aquelas mulheres jovens que, como Macabéa, também narram o que é “doer-se por dentro”. ${ }^{8}$

Paradoxalmente, pobreza, vida de retirante, migração do Nordeste para a grande e bela cidade do Sudeste, desamor, silêncio e retiro consigo mesma, um sem-jeito de viver - tudo isso não se separa de sinais não pouco expressivos de desejo de ser mais, de buscar a intensa transformação de si. A história de Macabéa é de uma pungência tal que não a imaginaríamos nessa condição numa narrativa televisiva (depois de já ser transformada em filme), sem perder muito a força que tem a escritura de Clarice Lispector. Porém, o que sucede é que a roteirização, a atuação de Regina Casé, os gestos, olhares e lembranças das moças nordestinas

${ }^{7}$ Talvez uma das mais emocionantes cenas do livro e da adaptação para TV seja esta: a colega de Macabéa no escritório, Glória, pergunta por que a moça nordestina lhe pede tanta aspirina. Macabéa responde: "É para eu não me doer, eu me doo o tempo todo”. Onde? "Dentro, não sei explicar” (Lispector, 1984, p. 72). As moças que participam no estúdio misturam-se à dor de Macabéa e contam, para Regina Casé, para as câmeras e para nós todos, como e em que medida também elas se “doem por dentro”.

${ }^{8}$ O filme homônimo, de 1985, foi estrelado por Marcélia Cartaxo e dirigido por Suzana Amaral. 
acabam por conferir outro tipo de força, diferente, ao que experimentamos na leitura do romance.

Emerge ali, naquela produção televisiva, uma ampliação de Macabéas, vistas ao mesmo tempo como individualidade e grupo; mostradas na pequenez e na grandeza - como se pudesse entrever-se no desejo de saber da personagem um vislumbre de felicidade clandestina possível, de alguém que pode e quer mais de si mesmo. Macabéa ligava a Rádio Relógio para saber "hora certa e cultura"; tinha prazer em colecionar anúncios de jornal; amava o mistério de palavras bonitas. As moças entrevistadas por Regina Casé não são diferentes; emocionam-se também consigo mesmas, expõem delicada e ternamente a própria dor, a história de sua travessia feita de asperezas e de esperanças singelas. E essas são apenas algumas das dezenas de situações narradas no romance e transportadas para o especial da TV. Diante delas, não posso me furtar a pensar que a narrativa de Clarice, no livro, no cinema e na TV, se apresenta ela mesma como se fosse uma caixa de ferramentas, como material que podemos ter sempre à mão, semelhante aos discursos verdadeiros propostos por Sêneca - aquele instrumental que estará ali, aprendido -, mas não cristalizado; vivo, portanto, prestes a ser usado, a qualquer momento, desde que estejamos dispostos a cuidar de nós mesmos. No aprisionamento dado pela condição social e econômica de Macabéa, tem lugar algo de liberdade, tão difícil de denominar e apontar quanto o olhar e o gestual da infância no cinema.

Ora, segundo Foucault, o cuidado de si se constituiu, na Antiguidade clássica, como o "modo pelo qual a liberdade individual - ou a liberdade cívica, até certo ponto - foi pensada como ética” (2004a, p. 268). Foucault segue dizendo, na entrevista à revista Concordia, que a partir de um certo tempo, na história ocidental o preceito do cuidado de si passou a ser "mal visto”, como se se tratasse de egoísmo, de interesse individual, como algo verdadeiramente a colocar-se sob suspeição - o que se deve em grande parte ao cristianismo, mas não só a ele. Ao mesmo tempo, a partir dos anos de 1970 passamos a ter acesso a uma avalanche de propostas de olhar narcísico sobre si mesmo. Foucault refere-se ao conhecido culto californiano do eu, estudado exaustivamente por autores como Cristopher Lasch (1983), por exemplo, e, entre nós, por Jurandir Freire Costa (2004).

Vale lembrar que, para Foucault, não se pode pensar todas essas práticas sem colocá-las no interior de relações de poder muito específicas. Mas este é o ponto principal: sempre haverá, nas relações de poder, exatamente relações; sempre haverá mais de um lado, e sempre uma certa forma de liberdade, mesmo nas condições mais adversas de desequilíbrio entre as duas partes. No episódio de A hora da estrela, mais uma vez o paradoxo: a hora da estrela é, contraditoriamente ou não, a hora da morte da personagem principal. Macabéa, assim como suas companheiras buscadas pela produção de Cena Aberta, é pobre e nordestina, mostra mínimos recursos para se defender, não parece mesmo estar "preparada para a vida”. Mas é justamente essa condição, imaginada por Clarice Lispector, que aparece no romance e na TV como um paradoxo, como imagem - olhares, gestos, palavras, ações - em que emerge, não se sabe precisamente em que momento e em que medida, naqueles rostos de mulheres em que nos reconhecemos, algo que nem nós nem as câmeras da TV Globo conseguimos capturar: fragmentos de subterfúgios, estilhaços de fuga, estratégias que parecem inverter toda a situação e apontar para outro modo de viver a própria vida.

\section{O que olhamos, o que nos olha, o que nos provoca}

Neste trabalho, fiz a análise de três produções audiovisuais - os filmes Despertar de uma paixão e Pequena Miss Sunshine, e um dos episódios da série Cena aberta, intitulado A Hora da Estrela, da TV Globo. O propósito foi articular concepções filosóficas aprendidas na leitura da obra $A$ hermenêutica do sujeito, de Michel Foucault, sobre o preceito do cuidado consigo e da meta de transformar a própria vida em obra de arte, de filósofos gregos e romanos estudados pelo autor. Com a precaução de não fazer a transposição tout court de conceitos e noções da 
Antiguidade clássica para tempos pós-modernos, o que desejei elaborar foi um pensamento a partir daquilo que os textos antigos provocaram em mim, tal qual foram elaborados nas aulas de Foucault, de 1982, no Collège de France. E o que eles provocaram, é bom enfatizar, produziu efeitos novos, totalmente distintos daquelas práticas dos primeiros séculos de nossa era.

Estamos sempre por dentro de jogos de verdade: e exatamente por se tratar de jogos, estamos falando de regras de produção de verdade, regras muito específicas e claramente situadas no tempo e no espaço. Tais regras supõem, obviamente, relações de poder. A problematização que desejei fazer neste trabalho foi pensar a formação docente também a partir de materiais oferecidos pela farta produção cinematográfica e televisiva a que temos acesso. Mais do que isso: pensar a formação docente seguindo as trilhas de olhares, gestos, sonorizações, roteiros, silêncios, enunciações - preferencialmente aquelas trilhas que, de alguma forma, jogam o mínimo possível com a linguagem da dominação, com o aprisionamento aos clichês do espetáculo tecnológico ou melodramático.

Fazer essa opção significou deixar em aberto o que exatamente fazer com essas coisas aqui ditas: nenhuma proposta concreta? Certamente não. Mas a complexidade e o paradoxal das narrativas escolhidas talvez possam sugerir uma espécie de programa de si e para si no que concerne à formação docente. No mínimo, fisgar possíveis espectadores em busca de tesouros singelos da produção cinematográfica e televisiva, atual ou de outras épocas, num trabalho de garimpo em nome da abertura a narrativas que nos provoquem transformação, na medida em que estas não cheguem para ocupar todos os espaços, que não se instalem para fazer de nossos imaginários imaginários em excesso. Mas que cheguem para fazer algo em nós, como tarefa filosófica crítica, pela qual não só questionamos os discursos e as ordens vigentes mas igualmente nos dedicamos a nos ocupar de nós mesmos. Tarefa pela qual se torne possível, nesse jogo aberto, receber generosamente imagens e sons desestabilizadores de verdades que cada vez mais constrangem nossos modos de ser e de estar neste mundo.

\section{Referências bibliográficas}

BADIOU, Alain. El cine como experimentación filosófica. In: YOEL, Gerardo (Org.). Pensar el cine 1: imagen, ética y filosofía. Buenos Aires: Manantial, 2004. p. 23-81.

CHAUí, Marilena. Janela da alma, espelho do mundo. In: NOVAES, Adauto (Org.). O olhar. São Paulo: Companhia das Letras, 1999. p. 31-63.

COSTA, Jurandir Freire. O vestígio e a aura. Rio de Janeiro: Garamond, 2004.

FISCHER, Rosa Maria Bueno. Cinema e TV na formação éticoestética docente. In: REUNIÃO ANUAL DA ANPED, 30., 2007, Caxambu. Anais... Rio de Janeiro: ANPEd, 2007.

FOUCAULT, Michel. A ética do cuidado de si como prática de liberdade. In: Ética, sexualidade, política. Ditos \& Escritos V. Trad. Elisa Monteiro e Inês Autran Dourado Barbosa. Rio de Janeiro: Forense Universitária, 2004a. p. 264-287.

. A hermenêutica do sujeito. Trad. Márcio Alves da Fonseca, Salma Tannus Muchail. São Paulo: Martins Fontes, 2004b.

FOUCAULT, Michel. O sujeito e o poder. In: RABINOW, Paul; DREYFUS, Hubert. Michel Foucault: uma trajetória filosófica. Para além do estruturalismo e da hermenêutica. Trad. Vera Portocarrero. Rio de Janeiro: Forense Universitária, 1995.

. Vigiar e punir: nascimento da prisão. Trad. Raquel

Ramalhete. 33. ed. Petrópolis: Vozes, 2007.

LARROSA, Jorge. Niños atravesando el paisaje. In: DUSSEL, Inês; GUTIERREZ, Daniela (Comp.). Educar la mirada. Políticas y pedagogías de la imagen. Buenos Aires: Manantial/FLACSO/ OSDE, 2006. p. 113-134.

LASCH, Christopher. A cultura do narcisismo: a vida americana numa era de esperanças em declínio. Trad. Ernani Pavaneli. Rio de Janeiro: Imago, 1983.

LISPECTOR, Clarice. A hora da estrela. Rio de Janeiro: Nova Fronteira, 1984.

MARCELLO, Fabiana de Amorim. Criança e imagem no olhar sem corpo do cinema. 2008. 237 f. Tese (Doutorado em Educação) - Faculdade de Educação, Universidade Federal do Rio Grande do Sul, 2008.

MERTEN, Luiz Carlos. Nos cinemas, o despertar de Kitty, papel da bela Naomi Watts. 2007. Disponível em: <http://www.estadao. com.br/arteelazer/cinema/noticias/2007/jun/21/265.htm>. Acesso em: 9 jul. 2007. 
XAVIER, Ismail. Cinema: revelação e engano. In:

O olhar e a cena. São Paulo: Cosac \& Naify, 2003. p. 31-57.

\section{Filmes e vídeos analisados}

Cena aberta (Episódio 1, A hora da estrela). Rede Globo de Televisão, 2003. Direção de Jorge Furtado.

Despertar de uma paixão (The painted veil). Estados Unidos-China, 2006. Direção de John Curran.

Pequena Miss Sunshine (Little Miss Sunshine). Estados Unidos, 2006. Direção de Jonathan Dayton e Valerie Faris.

ROSA MARIA BUENO FISCHER, doutora em educação, é professora da Universidade Federal do Rio Grande do Sul, no curso de pedagogia e no Programa de Pós-Graduação em Educação, e pesquisadora I-D do Conselho Nacional de Desenvolvimento Científico e Tecnológico (CNPq). Atua na área de educação e comunicação, com ênfase em estudos foucaultianos e relações entre mídia, juventude e processos de subjetivação na cultura. Publicações recentes: Televisão \& educação: fruir e pensar a TV (3. ed. Belo Horizonte: Autêntica, 2006); artigos em periódicos: “Mídia, juventude e memória cultural” (Educação \& Sociedade, v. 29, n. 104, out. 2008); "Mídia, juventude e educação: modos de construir o ‘outro’ na cultura” (Archivos Analíticos de Políticas Educativas - AAPE (on-line), v. 16, n. 2, jan. 2008). Pesquisa em andamento: "Educação do olhar e formação ético-estética: cinema e juventude”.E-mail: rosabfischer@terra.com.br

Recebido em novembro de 2007 Aprovado em agosto de 2008 